\title{
Intermittent Self Dilation - An Option For The Prevention of Urethral Stricture Recurrence After Filliform Follower Urethral Dilation
}

\author{
Shrestha NM
}

\begin{abstract}
Background: Urethral stricture and its recurrence is still a major problem in male. Several procedures are present for the treatment of the disease. Lapides introduced the concept of intermittent self dilatation (ISD) which has decreased the incidence of recurrence of urethral stricture if doing properly. The aim of the this study was to report the outcomes of ISD for the treatment of urethral stricture after Filliform follower urethral dilatation (FFUD). Method: This was a prospective comparative study, conducted in the department of surgery, urology unit from march 2013 to February 2016. Total of 49 patients were enrolled and were randomly divided into Group A and Group B. In Group A, all the patients were taught ISD with Nelaton Catheter after FFUD. In group B, all patients underwent only FFUD for urethral stricture. In both groups, Foley's catheter was removed after 2 weeks of FFUD. These patients who had difficulty In passing urine or having lower urinary tract syndrome after removal of catheter, were evaluated for urethral stricture recurrency by clinical symptoms, ultrasonography, urine test for culture and sensitivity, cystoscopy/urethrogram as necessarily. Result: In Group A, 4 patients out of 20(20\%)developed urethral stricture recurrency where as in Group B,18 patients out of $23(78.26 \%)$ developed urethral stricture recurrency. Therefore, the rate of urethral stricture recurrence is significantly more in group $B$ than the Group A ( $p<0.001)$. Conclusion: ISD is an effective way for the prevention of urethtral stricture recurrence after FFUD.
\end{abstract}

Key words: FFUD, ISD, recurrence urethral stricture

\section{INTRODUCTION}

Urathral Stricture is a scarring process involving either urethral mucosa / submucosaor spongy erectile tissue of the corposa. This scar reduces the internal size of the urethral lumen which causes blockage or reduction in the flow of urine leading to compications such as urosepsis and renal failure ${ }^{1}$. So it is still one of major problem in male population. In general, urethral stricture refers to mainly anterior urethral constriction. The lengthof stricture may vary from less than 1 centimeter to full length of it.

In previous days, Gonorrhoea was supposd to be the most common cause for stricture. However, at present concept has been changed. It is idiopathetic and iatrogenic disease. Unnecessary urethral catheterization and repeatedly urethral instrumentations are often cause stricture. Therefor, these metods should be minimized to prevent urethral stricture ${ }^{2}$. Other causes include noticed / unnoticed straddle injury, Balanitisxeroticaobliterans $(\mathrm{BXO})^{3}$. There are various treatment option which aimed to widen narrow part of urethra. However, the best technique has not been clearly defined yet ${ }^{4}$. Internal urethrotomy and urethral dilatation are the most commonly performed treatment for the urethral stricture. The other treatment options are laser urethrotomy, urethroplasty ${ }^{5}$.

\footnotetext{
Address for correspondence:

Dr. Nareshman Shrestha

Department of Surgery

Nepalgunj Medical College

Kohalpur, Banke, Nepal

Email: drnms1973@gmail.com
}

Optical internal urethrotomy by cold knife and laser are first line of surgical treatment for short length of urethral stricture ${ }^{6,7}$.

However, there is chance of recurrency of urethral stricture after any type of surgery for stricture. So needs some additional procedure to prevent from recurrency after primary treatment. Temporary intermittent self dilatation after any type of primary surgical treatment is also described by some authors for the prevention recurrence of $\mathrm{it}^{8,9}$.

Lapides introduced the conceptof self dilatation to prevent recurrence of urethral stricture ${ }^{10}$. ISD is the simple, short and cheap procedure $\mathrm{n}$ which patient himself catheterizes with well lubricated hydrophilic catheter or Nelaton catheter twice, once a day or in different time interval. Therefore, present study compares incidence of recurrency of urethral stricture with or without self dilatation after FFUD at Nepalgunj Medical College.

\section{MATERIALS AND METHOD}

It is a comparative study conducted in the Department of Surgery, Urology unit, in NGMC from March 2013 to February 2016. All patients having difficulty in passing urine, were examined with Ultrasonography, $x$ ray kidney ureter bladder (KUB), urine for routine, culture and sensitivity, retrograde urethrogram and cystourethroscopy. In patients who had stricture, Urethroscopy wasdone.Strictured site were located.guide wire inserted through the strictured area and gradual urethral dilatation was done with Filliform follower dilator up to $20 \mathrm{Fr}$. 16 FrFoley"s catheter was plasedwhich was kept for 2 weeks. After 2 weeks, Foley's catheter was removed. 


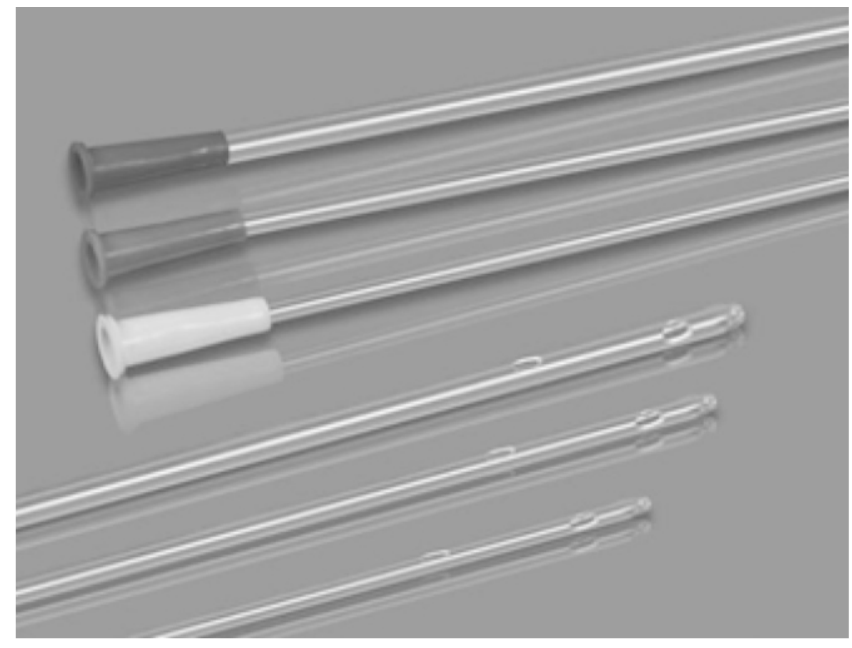

Figure 1: Nelaton catheter

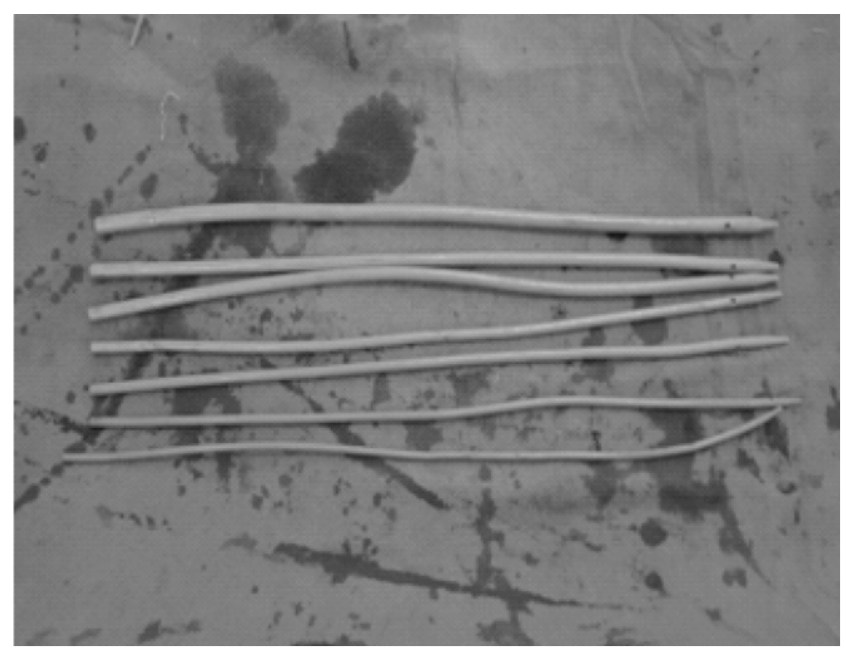

Figure 2: Filliform Follower Dilators

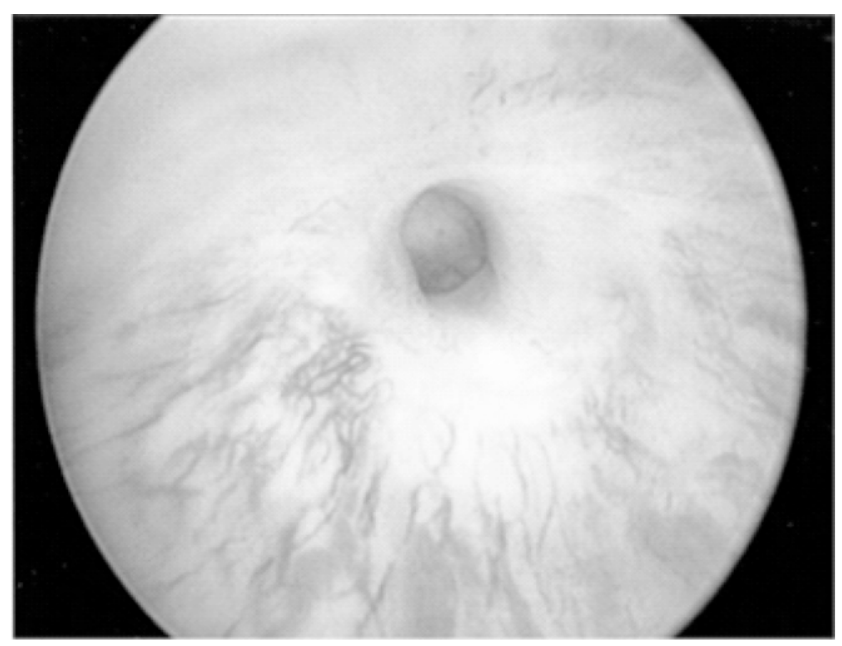

Figure 3: Cystoscopic view of urethral stricture

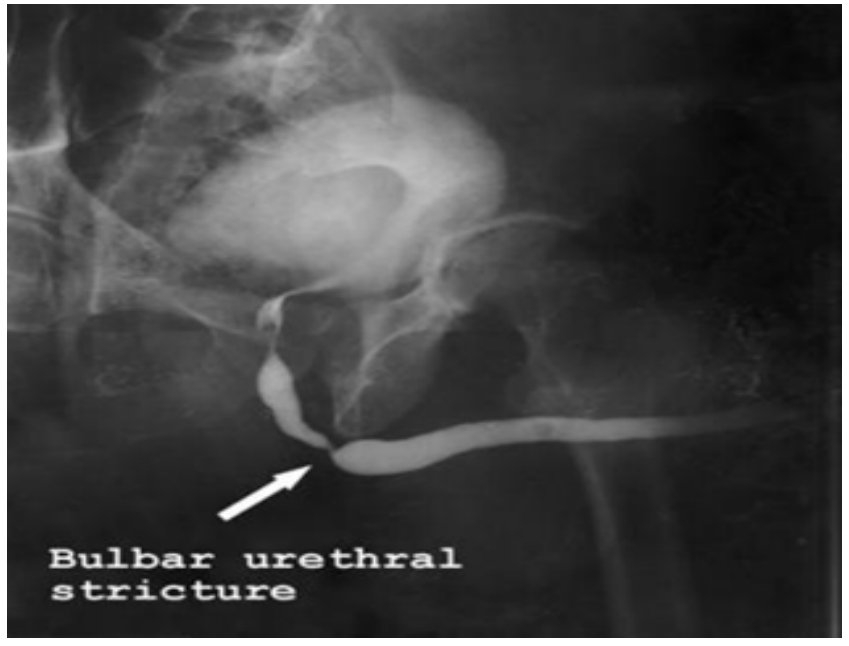

Figure 4: Urethrogram showing bulbar urethral stricture

\section{Inclusion criteria:}

Short stricture less than $1 \mathrm{~cm}$.

Patient willing for follow up

No prior history of stricture and dilatation.

Male patient

Age between 20 to 85 years.

Grouping and treatment:

After doing FFUD and the removal of Foley's catheter the patients in Group A were tought ISD with $16 \mathrm{Fr}$ Nelaton catheter. They underwent intermittent self dilatation once a day for 1 month then alternate day for next one month. Group B consisted the patients who underwent only FFUD but no ISD. Patients of both groups were observed for 3 months in each month or when he developed symptoms of LUTS or retention of urine.

Patients who presented with difficulty in passing urine or lower urinary tract syndrome (LUTS) were revaluated with ultrasonography, urine for cultue/sensitivity, $\mathrm{x}$ ray KUB. Cystoscopy and urethrogram were done only in those patients in whom the LUTS was present but the imagings and the urine culture were normal.

Data analysis was performed with SPSS version 17. For the parametric test of two groups, independent samples t-test was used. A p-value less than 0.05 was considered statistically significant $^{11}$.

\section{RESULT}

A total 49 patients were enrolled in this study however 43 patients completed this study. Group A consisted 25 patients in which 4patients discontinued ISD and 1 patient lost the follow up. Group B consisted 24 patients in which 1patient lost the follow up. In group A mean age of the patients was $49 \pm 14.261$ and in group $B$ the mean age was $51.09 \pm 13.714$. 
Urethral stricture recurrence rate:

In group A, out of 20 patients 6(30\%) patients even doing ISD complained ofLUTS at different time interval during follow up. These patients were investigated to find out the cause. In 2 patients urinary tract infection was found and 4 patients had urethral stricture. In group B , out of 23 patients, 18 (78.26\%) patients had LUTS and restricture formation on investigations $(p<0.001)$ Table I.

\begin{tabular}{|c|c|c|c|}
\hline Variables & Group A & Group B & P-Value \\
\hline Number of patients & 20 & 23 & \\
\hline $\begin{array}{c}\text { Urethral stricture } \\
\text { recurrence rate }\end{array}$ & $4(20 \%)$ & $18(78.26 \%)$ & $<0.001$ \\
\hline
\end{tabular}

\section{Table I : Urethral stricture recurrence}

\section{DISCUSSION}

This is the first prospective study conducted at Nepalgunj Medical College Kohalpur about the role of ISD for the prevention of recurrency of urethral stricture after FFUD. The present study has revealed that $20 \%$ in Group A patients developed a recurrence of urethral stricture within three months which was significantly less when compared with Group B patients in which $78 \%$ of patients developed recurrence of urethral stricture. But ISD did not prevent the recurrence in all patients. These findings are supported by the study of Khan S et al (2011) $)^{12}$. To evaluate the effect of ISD, this study did follow up of patient for 3 months and in the study of Khan $\mathrm{S}$ et. althe follow up was done for one year. Therefore, there is an evidence that till one year ISD decreases the reoccurance of urethral stricture. However, the long term follow up is needed to evaluate the long term effect of ISD in preventation of the urethral stricture.

The drop-out patients in the Group A is significantly higher than Group B. In Group A, 5 patients stopped to do self calllbrationdue tolaziness. These patients came again with LUTS. Cystoscopy revealed urethral stricture. This revealed that all patients do not have much interest to perform ISD with interest, however, the study of Mubasher $\mathrm{H}$ et, al. mentioned that ISD has considerabel social advantage and patients can easily handle the ISD at home. And is economy by reducing the cost by preventing recurrence of stricture ${ }^{13}$.

\section{CONCLUSION}

The present study showed that ISD is the effective method of reducing the stricture recurrence after FUDD. Therefore, all the patients must be taught about the intermittent self dilatation after FFUD.

\section{REFERENCES}

1. Jordan $G H$, Schlossberg SM. Surgery of the penis and urethra. Walsh PC, Retik AB, Vaughan ED, Wein AJ, editors.Campbell's Urology. 8th ed. London: Saunders 2002: 3886-952.
2. Fenton AS, Morey AF, Aviles R, Garcia CR. Anterior urethral strictures: aetiology and characteristics. Urology 2005; 6a5: 1055-8.

3. Mallo N, Garat JM, Santaularia J, Hernandez J. Urethrobalanitisxeroticaobliterans. EurUrol1978; 4: 9-12.

4. Andrich DE, Mundy AR. What is the best technique for urethroplasty? Eur Urol. 2008;54:1031-41.

5. Oosterlinck W. Treatment of bulbar urethral strictures a review, with personal critical remarks. ScientificWorldJournal. 2003;3:443-54.

6. Dutkiewicz SA, Wroblewski M. Comparison of treatment results between holmium laser endourethrotomy and optical internal urethrotomy for urethral stricture. IntUrolNephrol. 2012;44:717-24.

7. Jin T, Li H, Jiang LH, Wang L, Wang KJ. Safety and efficacy of laser and cold knife urethrotomy for urethral stricture. Chin Med J (Engl). 2010;123:1589-95.

8. Dubey $D$. The current role of direct vision internal urethrotomy and self-catheterization for anterior urethral strictures. Indian $J$ Urol. 2011;27:392-6.

9. Lauritzen M, Greis G, Sandberg A, Wedren H, Ojdeby G, Henningsohn L. Intermittent self-dilatation after internal urethrotomy for primary urethral strictures: a case-control study. Scand J UrolNephrol. 2009;43:220-5.

10. Lapides J,Diokno AC, silber SJ, Lowe B S clean, intermittent selfcatheterization in the treatment of urinary tract disease. $J$ urol $1972 ; 107: 458-61$

11. MarusteriM ,Bacarea V. Comparing groups for statistical differences: how to choose the right statistical test ?BiochemicalMedica.2010;20(1):15-32.

12. Khan S, Khan RA, Ullah A, Haq F, Rahmanet al. Role of Intermittent self catherisation (CISC) in the prevention of recurrent urethral strictures after internal optical urethrotomy. J Ayub Med CollAbbottabad 2011;23(2):22-25.

13. Akkoe A, Aydin C, Kartalmis M, Topaktas R. Use and outcomes of amplatz renal dilator for treatment of urethral strictures. Int.braz J urol.2016;42(2):356-64. 